\title{
Pengaruh Kecerdasan Emosional Terhadap Kinerja Pegawai Di Kantor Pelayanan Pajak
}

\author{
${ }^{1}$ Junaidi, ${ }^{2}$ Muhammad Azwar, ${ }^{3}$ Nurmaysaroh Lubis, ${ }^{4}$ Irna Bunga Permata Sari Rambe \\ ${ }^{1-4}$ Program Magister Manajemen, Fakultas Ekonomi, Universitas Islam Sumatera Utara
}

\author{
Article history \\ Received: 18 Nov 2020 \\ Revised: 17 Dec 2020 \\ Accepted: 4 Jan 2021 \\ *Corresponding Author: \\ Junaidi, Program Studi \\ Magister Manajemen, \\ Fakultas Ekonomi, \\ Universitas Islam Sumatera \\ Utara \\ Email: \\ Junaidi12@gmail.com
}

\begin{abstract}
Abstrak: Birokrasi menjadi instrumen penting dalam masyarakat yang kehadirannya tak mungkin terelakkan dengan konsekuensi logis untuk mensejahterakan rakyatnya. Berkenaan dengan upaya pelayanan dan mewujudkan kesejahteraan rakyat, birokrasi publik memberikan andil yang relatif besar. Melalui kecerdasan emosianal, maka kesadaran diri yang memandu seseorang mengakui dan menghargai perasaan diri sendiri dan orang lain, serta menerapkan dengan efektif dalam perilaku. Adapun masalah penelitian yaitu pengaruh kecerdasan emosional terhadap kinerja pegawai pada kantor pelayanan pajak madya medan. Metode pengumpulan data yang digunakan dalam penelitian ini dengan pendekatan survey melalui observasi, wawancara, pembagian kuesioner dan studi dokumentasi. Metode analisis data yang digunakan adalahanalisis regresi linier berganda. Populasi penelitian ini adalah seluruh pegawai Kantor Pelayanan Pajak Madya Medan yang berjumlah 126 orang. Hasil penelitian ini menunjukan bahwa Variabel kecerdasan emosional memiliki nilai p-value (pada kolom Sig.) $0,004<0,05$ artinya signifikan, sedangkan t hitung 2,989 > dari t tabel 2,008 artinya tidak signifikan. Hal ini berarti bahwa kecerdasan emosional berpengaruh signifikan terhadap kinerja pegawai.
\end{abstract}

Kata Kunci : Pengaruh, Kecerdasan Emosional, Kinerja pegawai, Pelayanan Pajak

\section{PENDAHULUAN}

Berkenaan dengan upaya pelayanan dan mewujudkan kesejahteraan rakyat, birokrasi publik memberikan andil yang relatif besar. Untuk mencapai tujuan yang mulia dari birokrasi, diperlukan kiranya pegawai yang handal dan cekatan dalam menangkap kebutuhan jaman yang semakin kompleks dewasa ini. Sejumlah tuntutan kemampuan tersebut merupakan kebutuhan dalam pengembangan sumber daya manusia aparatur pemerintah dalam birokrasi publik di Indonesia. Seperti halnya kecerdasan emosional. Menurut Svyantek (2003) kecerdasan emosional adalah kemampuan mengetahui perasaan sendiri dan perasaan orang lain, serta menggunakan perasaan tersebut menuntun pikiran dan perilaku seseorang. Dengan demikian kecerdasan emosional merupakan kesadaran diri yang memandu seseorang mengakui dan menghargai perasaan diri sendiri dan orang lain, serta menerapkan dengan efektif dalam perilaku. Hal tersebut mengisyaratkan bahwa orang yang memiliki kecerdasan emosional yang tinggi akan memiliki kemampuan yang tinggi pula dalam mengetahui dan memahami perasaan sendiri dan perasaan orang lain. Sehingga menuntun pikiran dan perilakunya untuk meningkatkan prestasi kerjanya ataupun lebih bijaksana dalam cara pemecahan masalah yang pada akhirnya akan berujung pada pencapaian kinerja yang tinggi.

Tirto (2003) menyatakan bahwa pencapaian kinerja hanya 20\% ditentukan IQ, sedangan $80 \%$ ditentukan oleh kecerdasan emosi (EQ-emotional quotient). Begitu pula disimpulkan oleh Robbins (2002:144), bahwa IQ sudah berkembang 50\% sebelum usia 5 tahun, 80\% berkembangnya sebelum 8 tahun dan hanya berkembang $20 \%$ sampai akhir remaja, 
sedangkan kecerdasan emosi (EQ) dapat berkembang tanpa batas waktu. Oleh karena, jika pimpinan dan manajer mengharapkan pencapaian kinerja yang maksimal di perusahaannya, maka upaya yang paling tepat dilakukan ialah membina diri untuk memiliki kecerdasan emosi yang baik.

Para ahli psikologi menganggap kecerdasan itu tergantung dari filsafat ilmu yang mendasarinya (Efendi, 2005). Sedangkan menurut Binet dan Simon, kecerdasan terdiri dari tiga komponen, yaitu kemampuan menggerakan pikiran dan tindakan, kemampuan untuk mengubah arah tindakan jika tindakan tersebut telah dilakukan dan kemampuan mengkritik diri sendiri (Efendi, 2005:90). Dimana dalam prakteknya mengadopsi model Salovey-Mayer membagi kecerdasan emosional ke dalam lima kecakapan emosi dan sosial yang terdiri dari: Kesadaran diri, pengaturan diri, motivasi, empati dan keterampilan social (Goleman, 2002). Kesadaran diri, pengaturan diri dan motivasi digolongkan kedalam kecakapan pribadi, sedangan empati dan keterampilan sosial digolongkan ke dalam kecakapan sosial.

\section{METODOLOGI PENELITIAN}

Metode pengumpulan data yang digunakan dalam penelitian ini dengan pendekatan survey melalui observasi, wawancara, pembagian kuesioner dan studi dokumentasi. Metode analisis data yang digunakan adalahanalisis regresi linier berganda. Populasi penelitian ini adalah seluruh pegawai Kantor Pelayanan Pajak Madya Medan yang berjumlah 126 orang. Populasi yang terdapat dalam penelitian ini berjumlah 126 dan presisi yang ditetapkan atau tingkat signifikansi 0,1 , maka besarnya sampel pada penelitian ini adalah :

$$
\begin{aligned}
n & =\frac{126}{1260,1^{2}+1} \\
& =56 \text { orang }
\end{aligned}
$$

\section{Teknik Pengumpulan Data}

Teknik pengumpulan data dilakukan dengan 2 (dua) cara yaitu :

1. Pengumpulan data primer

a. Wawancara

Peneliti melakukan wawancara langsung dan tidak langsung dengan pegawai Kantor Pelayanan Pajak Madya Medan yang dapat memberikan informasi yang berhubungan dengan objek penelitian agar diperoleh data yang diinginkan.

b. Kuesioner / Angket Penelitian

Dengan memberikan daftar pertanyaan/angket penelitian sesuai dengan data yang diinginkan kepada para responden yang berjumlah 95 orang.

2. Pengumpulan data sekunder

Pada metode ini, data yang telah dikumpulkan oleh lembaga pengumpul data dan dipublikasikan kepada masyarakat pengguna data. Dalam penelitian ini data diperoleh dari :

a. Studi Perpustakaan, yaitu memperoleh data pendukung dalam penelitian ini berdasarkan pada buku-buku, karya ilmiah yang relevan terhadap penelitian. 
b. Lembaga atau objek penelitian, yaitu memperoleh data penelitian dari Kantor Pelayanan Pajak Madya Medan seperti struktur organisasi dan uraian tugas jabatan.

\section{Pengujian Hipotesis}

Dalam penelitian ini untuk menguji hipotesis penelitian menggunakan analisis regresi linier berganda yaitu melihat pengaruh variabel independent (variabel bebas) terhadap variabel dependent (variabel terikat), dengan menggunakan persamaan matematis yaitu analisis regresi linier berganda dengan rumus :

$$
\mathrm{Y}=\mathrm{a}+\mathrm{b} 1 \mathrm{X} 1+\varepsilon
$$

Dimana :

$\begin{array}{ll}\mathrm{Y} & =\text { Kinerja pegawai } \\ \mathrm{a} & =\text { Konstanta } \\ \mathrm{X} 1 & =\text { Kecerdasan emosional } \\ \mathrm{b} 1, \mathrm{~b} 2, \mathrm{~b} 3 & =\text { Koefisien regresi } \\ \boldsymbol{\varepsilon} & =\text { Standard error }\end{array}$

\section{Uji F (Pengujian Simultan)}

Tingkat kepercayaan yang digunakan adalah 95\% atau taraf signifikan 5\% $(\alpha=0,05)$ dengan kriteria sebagai berikut :

a. Jika F hitung $>\mathrm{F}$ tabel dan probabilitas (nilai signifikan) $<$ tingkat signifikansi $5 \%(\alpha$ $=0,05)$ maka Ha diterima dan H0 ditolak berarti ada variabel independent secara bersama-sama mempunyai pengaruh yang signifikan terhadap variabel dependent.

b. Jika F hitung < F tabel dan probabilitas (nilai signifikansi) > tingkat signifikansi 5\% $(\alpha=0,05)$ maka H0 diterima dan Ha ditolak berarti ada variabel independent secara bersama-sama tidak mempunyai pengaruh yang signifikan terhadap variabel dependent. Dimana F tabel ditentukan dengan mencari derajat bebasnya yaitu df1=k-1 dan df2=N-k, dimana $\mathrm{N}=$ jumlah sampel dan $\mathrm{k}=$ jumlah variabel.

\section{Uji t (Pengujian Secara Parsial)}

Kriteria penggunaan uji $\mathrm{t}$

1. Jika $\mid \mathrm{t}$ hit $|<| \mathrm{t}$ tabel $\mid$, maka terima $\mathrm{HO}$ atau tolak Ha

2. Jika $\mid \mathrm{t}$ hit $|\geq| \mathrm{t}$ tabel $\mid$, maka tolak $\mathrm{H} 0$ atau terima $\mathrm{Ha}$

\section{Koefisien Determinasi $\left(\mathbf{R}^{2}\right)$}

Nilai koefisien determinasi adalah antara nol (0) sampai dengan satu (1). Nilai $\mathbf{R}^{2}$ yang kecil berarti kemampuan variabel-variabel independent dalam menjelaskan variasi variabel dependent amat terbatas. Nilai yang mendekati satu berarti variabel-variabel independent memberikan hampir semua informasi yang dibutuhkan untuk memprediksi variasi dependent. 
HASIL DAN PEMBAHASAN

Tabel 1. Statistik Deskriptif

\begin{tabular}{|c|c|c|c|c|c|c|}
\hline \multirow{2}{*}{ Instrumen } & \multicolumn{6}{|c|}{ Frekwensi (Persentase) } \\
\hline & 5 & 4 & 3 & 2 & 1 & Total \\
\hline 1. KP1 & 55,4 & 39,3 & 5,4 & 0 & 0 & 100 \\
\hline 2. $\mathrm{KP} 2$ & 33,9 & 66,1 & 0 & 0 & 0 & 100 \\
\hline 3. KP3 & 39,3 & 60,7 & 0 & 0 & 0 & 100 \\
\hline 4. $\mathrm{KP} 4$ & 50,0 & 39,3 & 10,7 & 0 & 0 & 100 \\
\hline 5. KP5 & 19,6 & 67,9 & 12,5 & 0 & 0 & 100 \\
\hline 6. KP6 & 35,7 & 64,3 & 0 & 0 & 0 & 100 \\
\hline 7. KP7 & 16,1 & 66,1 & 14,3 & 3,6 & 0 & 100 \\
\hline 8. KP8 & 46,4 & $\begin{array}{l}00,1 \\
536\end{array}$ & 0 & 0 & 0 & 100 \\
\hline 9. KP9 & 48,2 & & 0 & 0 & 0 & 100 \\
\hline 10. KP10 & 51,8 & $\begin{array}{l}51,8 \\
48,2\end{array}$ & 0 & 0 & 0 & 100 \\
\hline 1. KE1 & 5,4 & 57,1 & 35,7 & 1,8 & 0 & 100 \\
\hline 2. KE2 & 25,0 & 58,9 & 16,1 & 0 & 0 & 100 \\
\hline 3. KE3 & 17,9 & 71,4 & 10,7 & 0 & 0 & 100 \\
\hline 4. KE4 & 12,5 & 82,1 & 5,4 & 0 & 0 & 100 \\
\hline 5. KE5 & 16,1 & 58,9 & 23,2 & 1,8 & 0 & 100 \\
\hline 6. KE6 & 37,5 & 62,5 & 0 & 0 & 0 & 100 \\
\hline 7. KE7 & 37,5 & 62.5 & 0 & 0 & 0 & 100 \\
\hline 8. KE8 & 19,6 & 62,9 & 12,5 & 0 & 0 & 100 \\
\hline 9. KE9 & 28,6 & $\begin{array}{l}01,9 \\
714\end{array}$ & 0 & 0 & 0 & 100 \\
\hline 10. KE10 & 48,2 & 46,4 & 5,4 & 0 & 0 & 100 \\
\hline
\end{tabular}

Uji Kualitas Data

Tabel 2. Validitas

\begin{tabular}{llccc}
\hline \multicolumn{2}{l}{ Instrumen } & r-hitung & r-tabel & Keterangan \\
\hline 1) & KE1 & 0.595 & 0.263 & Valid \\
2) & KE2 & 0.545 & 0.263 & Valid \\
3) & KE3 & 0.619 & 0.263 & Valid \\
4) & KE4 & 0.629 & 0.263 & Valid \\
5) & KE5 & 0.646 & 0.263 & Valid \\
6) & KE6 & 0.494 & 0.263 & Valid \\
7) & KE7 & 0.412 & 0.263 & Valid \\
8) & KE8 & 0.571 & 0.263 & Valid \\
9) & KE9 & 0.480 & 0.263 & Valid \\
10) & KE10 & 0.403 & 0.263 & Valid \\
\hline 1) & KP1 & 0.427 & 0.263 & Valid \\
2) & KP2 & 0.627 & 0.263 & Valid \\
3) & KP3 & 0.616 & 0.263 & Valid \\
4) & KP4 & 0.386 & 0.263 & Valid \\
5) & KP5 & 0.528 & 0.263 & Valid \\
6) & KP6 & 0.590 & 0.263 & Valid \\
7) & KP7 & 0.492 & 0.263 & Valid \\
8) & KP8 & 0.721 & 0.263 & Valid \\
9) & KP9 & 0.668 & 0.263 & Valid \\
10) & KP10 & 0.726 & 0.263 & Valid \\
\hline
\end{tabular}




\section{Reliabilitas}

Tabel 3. Uji Reliabilitas Variabel

\begin{tabular}{lccc}
\hline Variabel & $\begin{array}{c}\text { Cronb } \\
\text { ach's } \\
\text { Alpha }\end{array}$ & $\begin{array}{c}\text { Batas } \\
\text { Reliabilitas }\end{array}$ & Keterangan \\
\hline Kecerdasan & 0.712 & 0.6 & Reliabel \\
Emosional & 0.738 & 0.6 & Reliabel \\
(X1) & & & Reliabel \\
Kinerja & & & Reliabel \\
Pegawai (Y) & & & Reliabel \\
\hline
\end{tabular}

Dari data tabel 3 di atas dapat dilihat bahwa hasil perhitungan uji reliabilitas menunjukkan alpha cronbach's pada masing-masing kolom variabel tersebut lebih besar dari 0,6 (batas reliabilitas) maka dapat dinyatakan instrumen tersebut reliabel.

\section{Pengujian Hipotesis}

Tabel 4. Pengujian Hipotesis dengan Uji t

\begin{tabular}{|c|c|c|c|c|c|c|}
\hline \multirow{2}{*}{\multicolumn{2}{|c|}{ Model }} & \multicolumn{2}{|c|}{$\begin{array}{c}\text { Unstandardized } \\
\text { Coefficients }\end{array}$} & \multirow[b]{2}{*}{ Beta } & \multirow[b]{2}{*}{$\mathrm{t}$} & \multirow[b]{2}{*}{ Sig. } \\
\hline & & $\mathrm{B}$ & Std. Error & & & \\
\hline \multirow[t]{2}{*}{1} & (Constant) & 18.342 & 4.242 & & 4.324 & .000 \\
\hline & $\begin{array}{l}\text { Kecerdasan } \\
\text { Emosional }\end{array}$ & .295 & .099 & .260 & 2.989 & .004 \\
\hline
\end{tabular}

Berdasarkan tabel di atas, diketahui nilai $t$ hitung dari masing-masing variabel independen secara parsial berpengaruh terhadap variabel dependen yaitu Variabel kecerdasan emosional memiliki nilai $p$-value (pada kolom Sig.) 0,004 $<0,05$ artinya signifikan, sedangkan t hitung 2,989 > dari t tabel 2,008 artinya tidak signifikan. Hal ini berarti bahwa kecerdasan emosional berpengaruh signifikan terhadap kinerja pegawai.

\section{Pengujian Hipotesis dengan Uji F}

Tabel 5. Hasil Uji Simultan (Uji F)

\begin{tabular}{r|r|r|r|r|r}
\multicolumn{1}{l|}{ Sum of Squares } & df & \multicolumn{1}{|c|}{ Mean Square } & \multicolumn{1}{c|}{ F } & \multicolumn{1}{c}{ Sig. } & \\
\hline 435.394 & 4 & 108.849 & 58.722 & $.000^{\mathrm{b}}$ \\
\hline 94.534 & 51 & 1.854 & & \\
\hline 529.929 & 55 & & & \\
\hline
\end{tabular}

Berdasarkan uji $\mathrm{F}$ atau uji Anova atau uji simultan di atas diperoleh $\mathrm{F}$ hitung sebesar 58,722 pada $\alpha=5 \%$ atau 0,05 dengan tingkat signifikan 0,000 karena nilai probabilitas $(0,000)$ jauh lebih kecil dari 0,05 maka model regresi dapat dipakai untuk memprediksi bahwa kecerdasan emosional (X1), sebagai variabel independen secara bersama-sama (simultan) berpengaruh terhadap kinerja pegawai (Y).

\section{Analisis Koefisien Determinasi $\left(\boldsymbol{R}^{2}\right)$}

Tabel 6. Hasil Analisis Koefisien Determinasi

\section{Model Summary}




\begin{tabular}{ll|l|l|l} 
Model & $\mathrm{R}$ & R Square & \multicolumn{1}{|c|}{$\begin{array}{c}\text { Adjusted R } \\
\text { Square }\end{array}$} & $\begin{array}{c}\text { Std. Error of the } \\
\text { Estimate }\end{array}$ \\
\hline 1 & $.906^{\mathrm{a}}$ & .822 & .808 & 1.361 \\
\hline a. Pred & & &
\end{tabular}

Hasil olahan pada tabel di atas terlihat nilai koefisien determinasi $\left(R^{2}\right)$ yang sudah disesuaikan (Adjusted $R$ Square) sebesar 0,808. Artinya 80,8\% variabel dependen (efektivitas kerja pegawai) dipengaruhi atau dijelaskan oleh variabel independen yaitu kecerdasan emosional dan sisanya sebesar 19,2\% (100\% - 80,8\%) dipengaruhi atau dijelaskan oleh variabel lain di luar variabel yang digunakan dalam penelitian ini.

\section{Hasil Persamaan Regresi}

Persamaan regresi yang telah dirumuskan dilakukan pengolahan data sehingga didapat persamaan akhir yaitu :

$$
Y=18,342+0,295 X_{1}
$$

Nilai besaran koefisien regresi $\beta_{1}$ sebesar 0,295 pada penelitian ini dapat diartikan bahwa variabel kecerdasan emosional (X1) berpengaruh terhadap kinerja pegawai (Y). Hal ini menunjukkan bahwa ketika kecerdasan emosional terpenuhi, maka kinerja pegawai akan naik 0,295 satuan.

\section{Pengaruh Kecerdasan Emosional Terhadap Kinerja Pegawai}

Secara parsial hasil penelitian ini menunjukan bahwa kecerdasan emosional berpengaruh terhadap kinerja pegawai di Kantor Pelayanan Pajak Madya Medan. Pengaruh tersebut menunjukkan bahwa kecerdasan emosional searah dengan kinerja pegawai atau dengan kata lain terpenuhinya kecerdasan emosional akan berpengaruh terhadap kinerja pegawai yang baik/tinggi. Pengaruh tersebut menunjukkan bahwa kecerdasan emosional mempunyai peranan yang penting dalam meningkatkan kinerja pegawai di Kantor Pelayanan Pajak Madya Medan.

Hal ini terbukti dari jawaban responden yang rata-rata setuju bahwa Pegawai akan mengungkapkan perasaannya dan akan memahami perasaan orang lain, Pegawai harus dapat mengendaikan amarahnya, Pegawai harus mempunyai sifat kemandirian, Pegawai harus mampu menyesuaikan diri dengan lingkungan kerjanya, Dengan sifat cerdas yang dimiliki maka kita akan disenangi orang, Pegawai mampu memecahkan masalah antar pribadi, Ketekunan kunci sukses seorang pegawai dalam bekerja, Kesetiakawanan sesama pegawai akan mendukung kinerja, Keramahan pegawai akan mendukung kesuksesan instansi, Sikap rasa hormat terhadap atasan atau sesama pegawai akan meningkatkan kinerja.

\section{KESIMPULAN}

Sesuai hasil analisis penelitian maka dapat diamil kesimpulan sesuai tujuan penelitian yang dikemukakan:

1. Kecerdasan emosional berpengaruh positif dan signifikan terhadap kinerja pegawai Kantor Pelayanan Pajak Madya Medan, hal ini didukung hasil analisis t hitung > ttabel $(2,989>2,008)$ pada $\mathrm{n}=56$ pada taraf sifgifikansi $95 \%$. 
2. Nilai F-hitung > F tabel $(58,722>2,55)$ hal ini menyatakan bahwa secara bersama-sama (multiple) terdapat pengaruh positif dan signifikan kecerdasan emosional terhadap kinerja pegawai Kantor Pelayanan Pajak Madya Medan. Dengan demikian hipotesis yang diajukan diterima kebenarannya.

\section{DAFTAR PUSTAKA}

Efendi, A. 2005. Revolusi Kecerdasan Abad 21. Kritik MI, EI,SQ, AQ \& successful intelligence atas IQ. Jakarta: Alfabeta

Goleman, D. 2002. Emotional Entellegent. Jakarta: PT. Gramedia Pustaka Utama

Robbinss, Stephen P. 2002. Essentials of Organizational Behavior (Terjemahan), Edisi Kelima. Jakarta: Penerbit Erlangga

Svyantek, D.J. 2003. Emotional Entellegence and Organizational Behavior, The International Journal of Organization Analysis 11(3): 167-169

Triton PB. 2006. SPSS 12.00 Terapan Riset Statistik Parametrik. Yogyakarta: Andi 